\title{
DISSENT
}

\section{The risk compensation theory and bicycle helmets}

\author{
J Adams, M Hillman
}

The Cochrane review by Rivara and the Thompsons found evidence that if you bang your head the consequences will be less severe if you are wearing a protective helmet. ${ }^{1}$ Based on this review they recommend that cyclists should be "encouraged" to wear helmets. The form of encouragement that they favour is compulsion.

We accept the principal finding of their review-that protective helmets protect in the event of an accident - but not the policy conclusions that they derive from it. The issue that divides us is risk compensation-does the behaviour of cyclists change as a consequence of wearing a helmet in ways that offset the protective benefit of helmets in accidents? After briefly referring to selected references from the safety literature on cycling, motorcycling, and driving, Rivara and the Thompsons assert that "the empirical evidence to support the risk compensation theory is limited if not absent". Certainly such evidence is limited or absent from the sources they choose to cite-with a notable exception which we discuss below. We find abundant evidence for risk compensation.

It is important to distinguish between evidence for risk compensation in generalwhich is overwhelming, and evidence relating to cycle helmets - which is limited. Let us consider the general evidence first. Rivara and the Thompsons recommend readers to consult James Hedlund's article in Injury Prevention entitled "Risky business: safety regulations, risk compensation, and individual behaviour". "We strongly support their recommendation. They quote James Hedlund: "I believe the evidence is overwhelming that every (our italics) safety law or regulation is not counterbalanced by compensating behaviour". But Hedlund also makes clear that the evidence is overwhelming that some laws and regulations, as well as safety measures voluntarily adopted, are counterbalanced by compensating behaviour. He states:

"We all change our behaviour in response to changes in our environment. Safety measures change our environment, so we may change our behaviour in response to them. . . . Never assume that behaviour will not change".

Hedlund helpfully sets out four rules for judging the circumstances in which behaviour might or might not change:

(1) If I don't know it's there I won't compensate for a safety measure. Bicycle helmets manifestly fail this test.

(2) If it doesn't affect me, I won't compensate for a safety measure. He poses the question "Do I feel safer wearing a bicycle helmet?" and suggests that if the answer is yes compensation is likely to occur.

(3) If I have no reason to change my behaviour, I won't compensate for a safety measure. Only if the behaviour of cyclists is completely unmotivated by concern for safety are they unlikely to compensate for a safety measure such as a helmet.

(4) If my behaviour is tightly controlled I won't compensate for a safety measure. He singles out driving as an activity that offers very considerable freedom to compensate. Cycling offers at least as much.

Hedlund advises "to reduce or eliminate risk compensation, use measures rating low on at least one factor". Cycling scores high on all four. Of all the cases Hedlund considers perhaps sports offer the closest comparators. He observes:

"Sports provide interesting examples of the interplay between injury prevention, compensation, and control. In many sports, such as ice hockey and American football, players are required to wear protective equipment. Some players have compensated by acting more violently within the confines of the rules. In some instances this has led to rules changes to control player actions more tightly".

Cyclists, like hockey and football players, are acutely sensitive to the likelihood that a miscalculation can result in serious injury, and govern their behaviour accordingly. We find it highly probable, in the absence of any change in propensity to take risks, that cyclists will respond like hockey and football players to measures that reduce the severity of the consequences of miscalculation.

Hedlund offers two further bits of useful advice:

(1) Consider system effects. Cycle helmet laws have led to a decrease in cycling; after it became compulsory to wear helmets in Australia, the level of cycling fell by about twice as much as did the number of cyclists admitted to hospital for the treatment of head injury. ${ }^{3}$ Other studies have found that the health benefits of cycling, measured in years of life gained, far outweigh the injury risks measured in years of life lost ${ }^{4}$ - by about 20 to $1 .^{5}$ By concentrating attention on the need to protect cyclists from head injuries Rivara and the Thompsons encourage the view of cycling as an inherently dangerous activity. Other countries, most notably Denmark and the Netherlands, demonstrate that, by making proper 
provision, cycling by largely helmetless cyclists can be made much safer.

(2) Don't over-predict benefits: "many injury prevention measures promise more benefits than they can deliver". Promises that deny the existence of risk compensation are almost certainly committing this offence.

Rivara and the Thompsons assert that "there have been no systematic reviews of the evidence for the relevance of risk compensation to bike helmets". So, ignoring Hedlund's "rules", and contrary to Hedlund's advice, they simply assume that there is no behavioural response to the protection afforded by cycle helmets.

The empirical difficulty with establishing the relevance of risk compensation to cycle helmets is that, compared with other activities such as motoring, there is a shortage of reliable data. Information about exposure is limited and difficult to interpret-the exposed population includes everyone from purposeful adults commuting on bicycles to small children using them for recreation rather than transport. There are few reliable surveys of helmet use. The jurisdictions in which helmet wearing is compulsory are few, and the level of cycle use in these jurisdictions is generally low. What is known is that helmet wearing rates are very low in countries such as Denmark and the Netherlands, where cycle use is high, and that cycling in these countries is much safer.

So Rivara and the Thompsons turn to argument by analogy, asserting that experience of motorcycle helmet laws provides support for their cycle helmet campaign. They say that motorcyclists are also vulnerable road users "since motorcycle crashes usually result in serious injury [only] to the motorcyclists themselves and not to cars and other motor vehicle passengers". The curious omission of pedestrians (and cyclists) from the list of motorcycle accident victims ignores the significant threat that they pose to the most vulnerable. Plowden and Hillman found that two wheeled motor vehicles, per mile driven, were five times more likely than cars to cause the death or serious injury of a pedestrian. ${ }^{6}$ Nevertheless they proffer in support of their views "the natural experiment" in the United States in which some states passed and repealed motorcycle helmet laws and others did not. Here we find another curious omission. They make no mention of Adams' review of this experiment that found that motorcyclist fatalities increased by more in states that did not repeal their laws than in those that did. ${ }^{7}$

Their brief review of evidence relating to seat belts is equally selective. They complain that a four page discussion of seat belt legislation in a 49 page paper on the management of risk and uncertainty by Adams $^{8}$ was not a proper systematic review because it did not "evaluate all available research". This short discussion did not purport to be a comprehensive review of the subject. For a much fuller discussion of seat belts and risk compensation the reader is referred to various publications by Adams $^{7-13}$ and Hillman et al. ${ }^{14}$

There is now an intractable problem for those studying road safety in separating the wheat from the chaff. It is no longer possible to evaluate "all available research". Hedlund reports a literature search on nine motor vehicle injury prevention strategies that turned up 54078 titles or abstracts. Most of these he suggests do not pass minimal standards of scientific rigour or quality. Faced with such an enormous volume of mostly poor quality research one must resort to crude filtering devices. One such filter might be to reject out of hand all studies that reject out of hand the possibility of risk compensation.

1 Thompson DC, Rivara FP, Thompson R. Helmets for preventing head and facial injuries in bicyclists (Cochrane review). The Cochrane Library, Issue 3, 2000. Oxford: Update Software.

2 Hedlund J. Risky business: safety regulations, risk compensation, and individual behavior. Inj Prev 2000;6:82-90.

3 Robinson D. Cycle helmet laws-facts, figures and consequences. Proceedings of the Velo Australis Conference. Perth, 1996. Freemantle: Promaco Conventions, 1996.

4 British Medical Association. Cycling towards health and safety. Oxford: Oxford University Paperbacks, 1992

5 Hillman M. Cycling and promotion of health. Policy Studies 1993:14:49-58. 6 Plowden S, Hillman, M, Danger on the road: the needless
scourge. London: Policy Studies Institute, 1984 (No 627 , scourge. London:
table II.3, p 78)

7 Adams J. Public Safety legislation and the risk compensation hypothesis: the example of motorcyle helmet legislation. Environment and Planning C 1983;1:193-203.

8 Adams J. Cars, cholera and cows: the management of risk and uncertainty. Washington, DC: Cato Institute, No 335, March 1999.

9 Adams J. The efficacy of seatbelt legislation. Society of Automotive Engineers, Transactions. Warrendale, PA: Society of Automotive Engineers, 1982: 2824-38.

10 Adams J. Evaluating the effectiveness of road safety measures. Traffic Engineering and Control June 1988: $344-52$.

11 Adams J. Risk homeostasis and the purpose of safety legislation. Ergonomics 1988;31:407-28.

12 Adams J. Seatbelt legislation: the evidence revisited. Safety Science 1994;18:135-52.

13 Adams J. Risk. London: UCL Press Ltd, 1995: 113-34.

14 Hillman M, Adams J, Whitelegg J. One false move: a study of children's independent mobility. London: Policy Studies Institute, 1990.

Response from Thompson, Thompson, and Rivara We are pleased that Mayer Hillman and John Adams accept the central point of our Cochrane systematic review - that bicycle helmets are effective in decreasing head injuries to cyclists. They disagree, however, with our conclusion that the use of helmets should therefore be encouraged based on our differing views of the evidence for risk compensation. They claim there is solid evidence for this hypothesis. We believe there is not and that we will only know this once a systematic review of risk compensation is conducted. Instead of being scientific, their arguments are based mainly on theory, philosophy, or expert opinion. We do not accept their proposition that "it is no longer possible to evaluate all the available research". We believe a systematic review could sift the empirical evidence. A systematic review is not based on expert opinions, theoretical discussions, narrative literature reviews, or positions taken by professional groups, and neither Adams' nor Hillman's publications include systematic reviews. A systematic review does not "resort to crude filtering devices"; it employs explicit inclusion and exclusion criteria and sets forth the rules of evidence and analytical processes before any of the evidence is examined. ${ }^{1-5}$ Clearly, it is time for an impartial body to examine the applicability of risk compensation theory to the use of bicycle helmets, 
and other areas where it has been invoked. A properly conducted systematic review that follows the criteria established by the Community Preventive Services Task Force recommendations can provide solid scientific evidence to support or disprove this theory. ${ }^{3-5}$ If risk compensation is the "real deal" after a recognized group examines the evidence systematically, we will accept that the proven benefits of bicycle safety helmets are outweighed by the negative effects.
1 Berg AO, Atkins D, Tierney W. Clinical practice guidelines in practice and education. 7 Gen Intern Med 1997;12 (suppl in practice and $25-33$.

2 Straus SE, Sackett DL. Using research findings in clinical practice. BMF 1998;317:339-42.

3 Briss PA, Zaza S, Pappaioanou M, et al. Developing an evidence-based guide to community preventive servicesmethods. Am f Prev Med 2000;18(1S):35-43.

4 Zaza S, Wright-De Aguero LK, Briss PA, et al. Data collection instrument and procedure for systematic reviews in the Guide to community preventive services. Am $\mathcal{F}$ Prev Med 2000;18(1S):44-74.

5 Carande-Kulis, VG, Maciosek MV, Briss PA, et al. Methods for systematic reviews of economic evaluations for the guide to community preventive services. Am F Prev Med 2000;18(1S):75-91.

\section{Drinking and walking}

An intoxicated pedestrian in Warrenville, IL, faces multiple traffic charges for staggering on to a street and causing a fatal crash, the Cook County Daily Herald reported. James A Browne, 31, was charged with being an intoxicated pedestrian on a road and failing to yield to traffic. According to police, Browne staggered onto the road, causing Irene Sanders of Mayfield to swerve and hit another car head-on. Sanders' sister and friend died as a result of injuries suffered in the collision. Authorities said Browne had been drinking at several friends' houses. He had a blood alcohol level of 0.398, more than five times the legal limit. Browne also faces civil suits from the drivers of both cars.

On a related note, the new law of the land in the United States is 0.08 blood alcohol content. This federal measure was signed by President Clinton last October. States that do not adopt 0.08 as their own impaired driving standard by 2007 will have their federal highway aid slashed. As of the signing, only 18 states had such a standard; the rest have been served notice.

\section{An old sad story ...}

In his account of "The Way West", a description of the 1841 expedition to the American west, in a recent National Geographic, John G Mitchell wrote: "Disease was the number one killer ... [but there was also] death by accidental gunshot, inasmuch as the emigrants tended to be as richly endowed with firearms as they were inept in the proper handling of them. McBride wrote of a man ... whose "jaw was shot away when a loaded pistol fired from his breast pocket". He adds "... the only one to perish on the trail was a young man ... who, in the act of drawing a rifle muzzle-first from his wagon, managed to trip its hammer" (National Geographic, September 2000, California Trails, Blazing the Way West).

\section{Sweet news for lollipop patrols}

School crossing patrols have been given wider powers to help people cross the road safely, England's Road Safety Minister, Lord Whitty, announced in January. Until now, "lollipop people" could only stop vehicles to help schoolchildren cross the road. Under new provisions in the Transport Act, school patrols can now stop traffic to enable anyone to cross the road safely. The new legislation also enables them to patrol at any time-until now they could only patrol between 0800 and 1730. Lord Whitty said: "School crossing patrols are a valuable part of our daily lives that can too easily be taken for granted. These amended powers will enhance their authority and enable them to help children of all ages as well as adults, including disabled people in wheelchairs, to cross our roads. I hope that they also send a clear and unequivocal message to any drivers who selfishly and irresponsibly ignore their signal to stop, putting people's lives at risk, that they have the statutory authority to stop traffic and the law will back them up".

(Editor's note $(M H)$ : If anyone is wondering what a "lollipop person" is, I should explain that they are more correctly called school crossing patrols. They are known by their more light hearted name because the Stop sign that they carry resembles a large lollipop - to people with very poor eyesight!) 